DEPARTMENT OF COMMERCE BUREAU OF STANDARDS

George K. Burgess, Director

TECHNOLOGIC PAPERS OF THE BUREAU OF STANDARDS, No. 315

[Part of Vol. 20]

\title{
NONDESTRUCTIVE TESTING OF WIRE HOISTING ROPE BY MAGNETIC ANALYSIS
}

BY

R. L. SANFORD, Physicist

Bureau of Standards

April 16, 1926

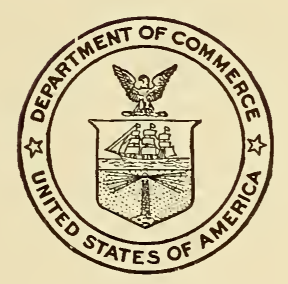

PRICE, 10 CENTS

\$1.25 PER VOLUME ON SUBSCRIPTION

Sold only by the Superintendent of Documents, Government Printing Office

Washington, D. C.

WASHINGTON

GOVERNMENT PRINTING OFFICE 



\title{
NONDESTRUCTIVE TESTING OF WIRE HOISTING ROPE BY MAGNETIC ANALYSIS
}

\author{
By R. L. Sanford
}

\begin{abstract}
In an endeavor to meet the great need for a reliable nondestructive method for the testing of wire hoisting rope the Bureau of Standards has conducted an investigation of the possibilities of magnetic analysis for this purpose. The investigation has been of a fundamental nature, consisting in a study of the magnetic properties of steel wire of the kind used in the manufacture of wire rope and the effect on them of deterioration due to various causes. The effects of stress, wear, and fatigue were studied. While it is evident that there is a very close connection between the magnetic and mechanical properties of steel, the relationships are so complex that much more study will be needed before the results of magnetic tests can be interpreted with a sufficient degree of certainty to warrant their use as a practical method for the routine inspection of wire rope.
\end{abstract}

\section{CONTENTS}

II. Magnetic analysis

III. Magnetic exploration 499

IV. Effect of stress.... 504

V. Effect of wear

VI. Effect of repeated stress

VII. Other effects

VIII. Summary and conclusions. 516

\section{INTRODUCTION}

It is difficult to tell just when a hoisting rope should be removed from service and a new one substituted. While it is desirable to utilize the full life of the rope, it is dangerous and oftentimes very expensive to leave a rope in place too long. The resulting damage may amount to many times the cost of putting in a new rope before the end of the useful life of the old one has been reached, to say nothing of the life hazard. By the present methods of visual inspection it is impossible to ascertain the conditions of a rope with certainty. The inspector must depend upon his judgment, based upon accumulated experience, together with certain arbitrary rules with regard to the number and distribution of broken wires. Under these 
conditions it is not at all surprising that occasionally ropes fail soon after being pronounced safe by a competent inspector. This is not necessarily due to any fault on the part of the inspector, but rather to the lack of an adequate testing method by means of which the true condition of the rope can be determined.

In an endeavor to meet the need for such a testing method, the Bureau of Standards, during the two-year period beginning July 1, 1923, carried on an investigation on nondestructive methods for testing wire hoisting rope. This work was supported by a special appropriation granted by Congress at the urgent request of important interests concerned with the use of wire rope for hoisting. Contact with these interests was maintained through an advisory committee to the bureau composed of representatives of various national technical societies and experts in the manufacture, use, and inspection of wire rope. Before starting the work a meeting of this committee was held, at which the problem was discussed and various physical properties which might be made the basis of a nondestructive test were considered. It was agreed that magnetic analysis appeared to offer the greatest promise and that this should be given first attention. Accordingly, the investigation has been devoted mainly to a study of magnetic analysis with reference to its use as a nondestructive method for testing wire rope. In view of the fact that the appropriation was not continued beyond the two-year period, it seems desirable to present at this time a brief discussion of magnetic analysis with special reference to the testing of wire rope, together with a report of the results obtained during the progress of the investigation.

\section{MAGNETIC ANALYSIS}

By magnetic analysis is meant testing by magnetic methods and using the results thus obtained as criteria of the mechanical quality or condition of the material so tested. Obviously, this method can only be applied to ferromagnetic materials, and thus far attention has been given primarily to steel and steel products.

The expectation that use can be made of the results of magnetic tests is based upon the fact that any treatment which alters the mechanical properties of a piece of steel to a measurable extent at the same time changes its magnetic properties. Although no exception to this general principle has been found, the magnetic properties of iron and steel are so sensitive to many influences which do not affect the other physical properties to a corresponding degree that the estimation of mechanical quality in terms of the results of magnetic tests has proven to be very difficult. This condition has thus far placed a serious limitation on the industrial application of magnetic analysis as a method of routine inspection. 
During the past few years a number of investigations have been carried out on various phases of magnetic analysis, and several methods of magnetic testing have been developed. ${ }^{1}$ In the investigation here reported main attention has been given to the methods of magnetic exploration and the interpretation of the test results.

\section{MAGNETIC EXPLORATION}

$\mathrm{B}_{y}$ magnetic exploration is meant the determination of the degree of magnetic uniformity along the length of a specimen. Since any irregularity in the mechanical properties of a specimen is accompanied by a corresponding irregularity in its magnetic properties, this

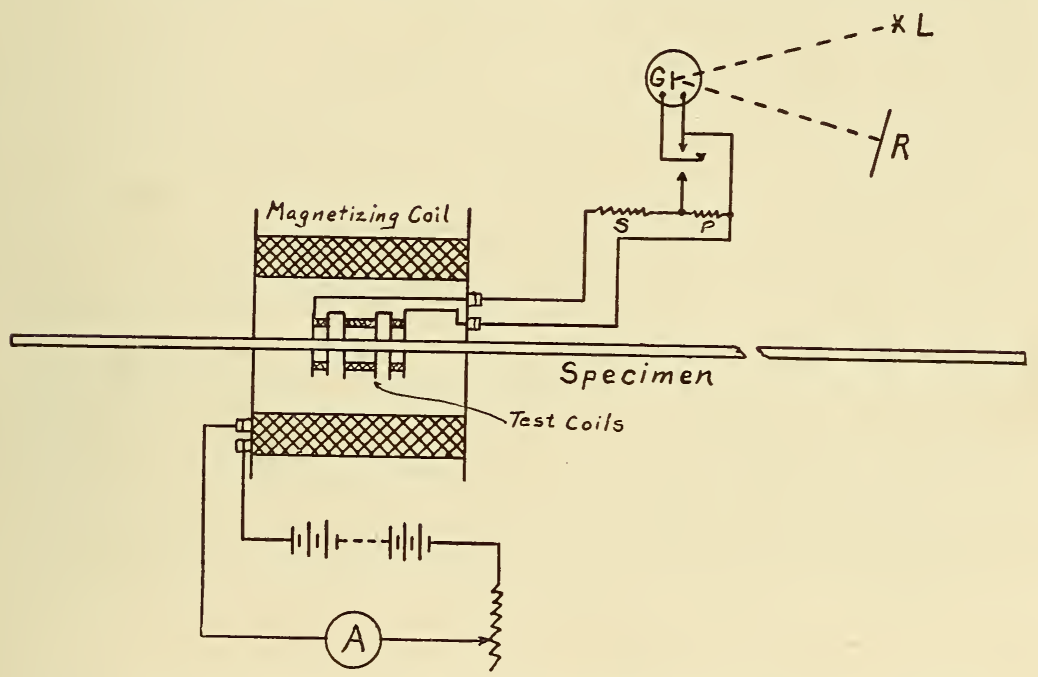

FIG. 1.-Diagrammatic representation of magnetic exploration apparatus

method at once suggests itself as a means for detecting flaws and imperfections.

The apparatus by which magnetic explorations are carried out consists essentially of (1) a magnetizing soleniod surrounding the specimen, (2) a test coil connected to an indicating instrument, and (3) means for producing relative motion between the coils and the specimen. In most cases the apparatus is arranged to record the deflections of the indicating instrument photographically. Figure 1 is a diagrammatic representation of the apparatus.

The magnetizing coil used in the present investigation consisted of 3,007 turns of No. 17 silk-enamel-covered copper wire wound on a fiber form approximately $20 \mathrm{~cm}$ (8 inches) long and $3.8 \mathrm{~cm}\left(1 \frac{1}{2}\right.$ inches) inside diameter. The magnetizing field at the middle of the

\footnotetext{
${ }^{1}$ Sanford, Trans. Amer. Soc. for Steel Treating, 5, p. 577; 1924.
} 
coil was approximately 191 times the current in amperes. There was also an outer auxiliary winding of 1,189 turns.

Several test-coil systems were used during the course of the investigation. These coils were wound on interchangeable fiber forms which could be mounted within the magnetizing solenoid. The test coils used were either single, double, or triple. The electromotive force induced in a single coil depends upon the rate of change in the magnetic flux in the specimen which is linked with the test coil. The disadvantage of this type of test coil is that changes of flux, due to fluctuations in the magnetizing current, give indications which can not be distinguished from those caused by irregularities in the material itself.

In order to overcome this difficulty, the test.coil may be in two parts, each of the same number of turns, and located at equal distances from the middle of the magnetizing coil. The two parts are wound in opposite directions so that any electromotive forces induced in one part, due to fluctuation in the magnetizing current, are neutralized by equal and opposite electromotive forces induced in the other part. When the variation in flux linkage is caused by irregularities in the material, however, the resulting electromotive forces induced in the two parts of the coil do not occur at the same time and deflections are produced in the indicating instrument first in one direction and then in the other. The triple coil consists of three parts, one located at the middle and the others at equal distances either side of it. The middle part has twice the number of turns that there are on each of the end parts. The windings are so arranged that the effect of the middle part is opposed to that of the two end parts, which are both wound in the same direction. The object of the three-part coil is to neutralize, in so far as possible, the effect of the decrease in flux due to the self-demagnetizing effect as the end of the specimen is approached. With the triple coil, the electromotive forces due to an irregularity in the specimen give three deflections, one in one direction and two in the other. With the two and three part coils, the magnitude of the deflection due to an irregularity in the material depends not only upon the magnitude of the irregularity, but also upon its extent and upon the spacing of the coils. For this reason calibration is not possible with the multiple coils and the results can not be expressed on a quantitative basis. Although all three types of test coil were used in the course of the investigation, the majority of the tests were made with a single coil, because the results were less complicated and could be expressed whenever desired on a quantitative basis. Compensation for slight fluctuations in magnetizing current was made by a duplicate magnetizing solenoid and test coil connected in series with the main coils and in which was inserted a sample of material similar to that under test. This method of com- 
pensation was found to be effective for the slight current fluctuations occurring during the tests. The apparatus is shown in Figure 2.

The magnetizing solenoid and test coil were mounted on a carriage which was moved along on a horizontal track by means of an electric motor. The wire specimens were suspended horizontally over the track, and means were provided for varying and measuring the tension in the wire. While this method of producing relative motion of the specimen and coils has been found the most convenient in the laboratory, in the field the coils would be stationary with the rope running through them.

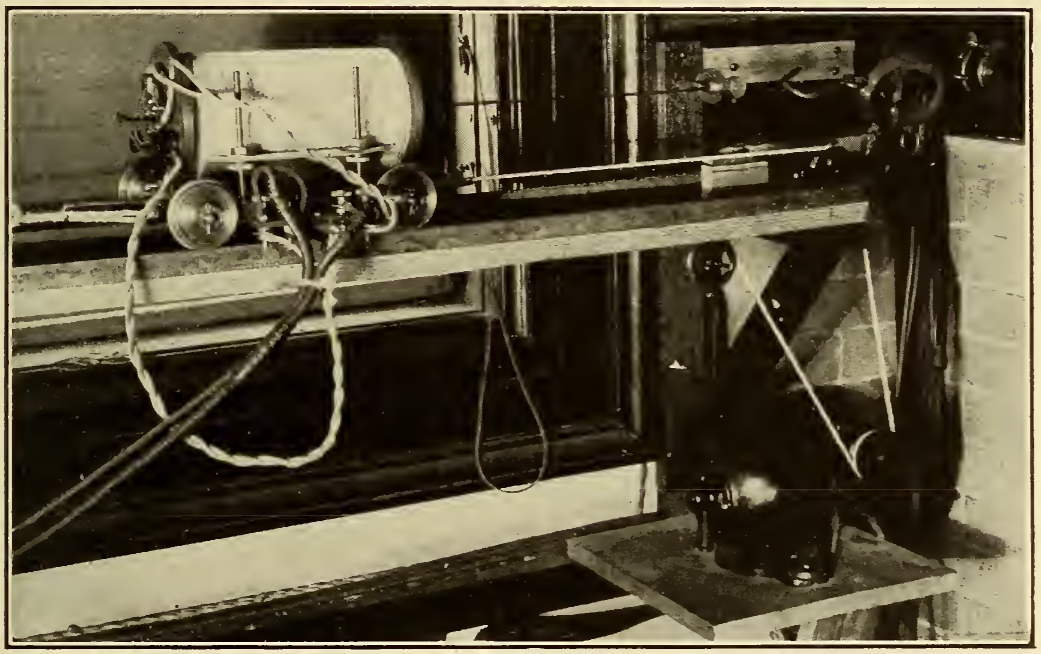

FIG. 2.-Magnetic exploration apparatus

The character of the record obtained depends not only upon the type of test coil used, but also upon the indicating instrument. A reflecting galvanometer of the moving-coil type is generally used. If the instrument has a short period and is critically damped, the instrument behaves as a voltmeter, and the deflection at any instant is proportional to the rate of change of flux linked with the test coil. This rate depends not only upon the local variations in the magnetic permeability or cross section of the specimen, but also upon the speed with which the coil is traveling. If the galvanometer is heavily overdamped so that the principal control is electromagnetic, then the instrument behaves as a fluxmeter, and the deflection at any instant is proportional to the total change in flux linkage since the start. The indication is then practically independent of speed. The degree to which this condition is realized depends upon the ratio between the electromagnetic control and the torsional control of the suspension. The heavily overdamped galvanometer has been found most satisfactory for magnetic exploration. 
In Figure 3 is shown the recorder, together with the apparatus for electrical control and calibration. The photographic record is made on a strip of bromide paper by means of a spot of light reflected upon it from the instrument mirror. A roll of paper is carried in the top of the magazine and is carried along by rollers driven by an electric motor at a speed proportional to that of the magnetizing coil along the length of the specimen. The paper runs into a detachable lighttight compartment at the bottom, and, when a record has been made, the paper can be cut off and taken to the dark room to be developed. Contacts are provided on the apparatus so that an auxiliary lamp is flashed within the camera at each foot of travel of the coils. This produces lines on the record by means of which

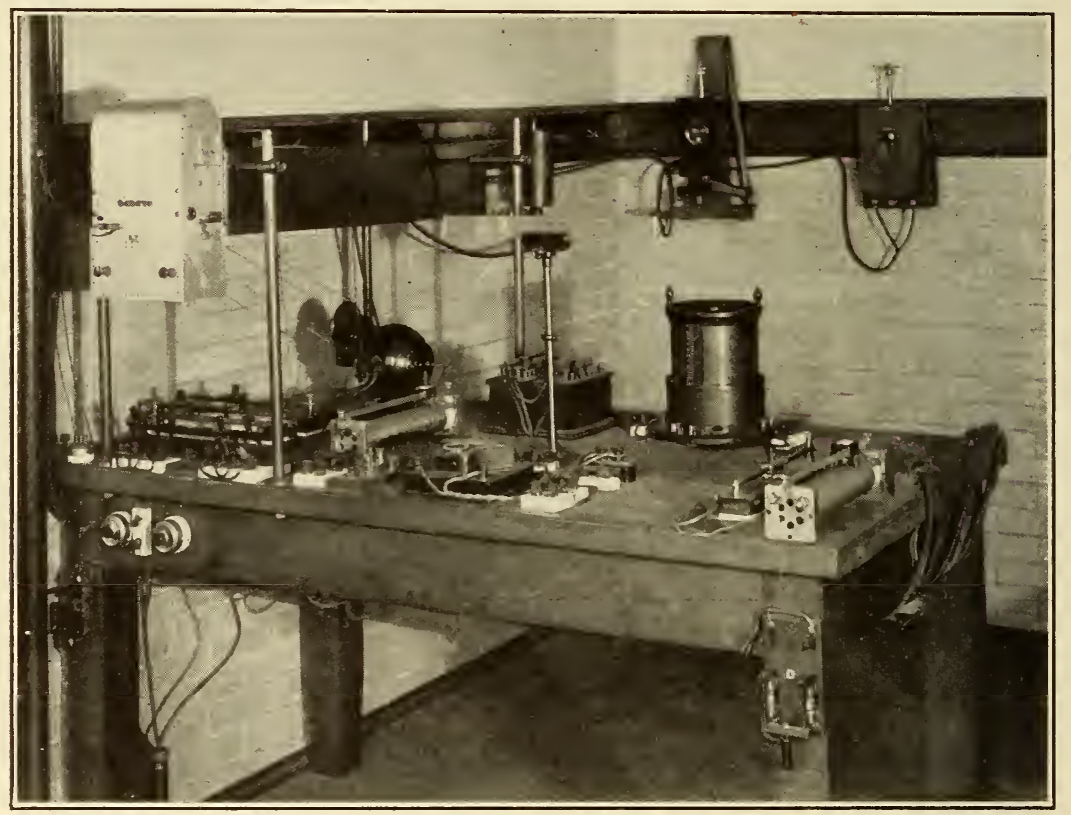

FIG. 3.-Recorder and control apparatus for magnetic exploration

irregularities can be located. Calibration is made by means of a variable mutual inductance whose secondary is in the test-coil circuit. If the specimen is magnetically uniform along its length, the spot of light remains stationary as the coils are moved along, and the resulting record is a straight line. Departures from a straight line indicate nonuniformities in the specimen.

In Figure 4 are shown typical records made with the magnetic exploration apparatus. These records are illustrative of the difficulty encountered in the interpretation of the results of magnetic exploration. No. 1 is the record obtained for a sample of stream line wire used in airplane construction. Although variations in 
magnetic permeability of considerable magnitude are indicated, this wire showed no signs of weakness in actual service, and no flaw or imperfection was revealed by any other physical test.

Record No. 2 shows at $A$ the effect on another sample, otherwise comparatively uniform magnetically along its length, of bending the wire at right angles and straightening again. It is seen that this really serious defect causes a magnetic variation no greater in magnitude than those found in the wire of record No. 1. These two

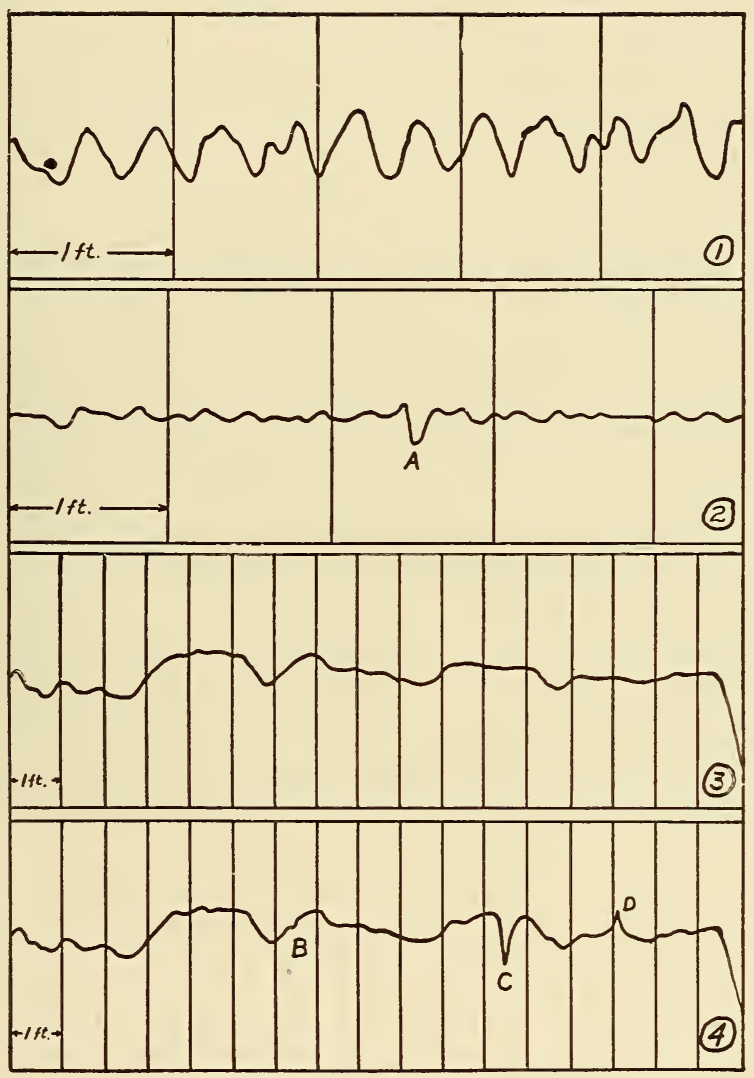

FIg. 4.-Typical magnetic exploration records

records were made on samples of the same dimensions using the apparatus at the same sensitivity. This lack of proportionality between the magnetic indication and the degree of the mechanical defect is one of the greatest obstacles to be overcome in the interpretation of the records for practical purposes.

Nos. 3 and 4 are records for the same wire before and after introducing artificial flaws at $B, C$, and $D$. At $B$ a notch was filed in the wire about one-third of the way through. At $C$ the wire was bent and straightened, while at $D$ the wire was heated with a burning $83333^{\circ}-26 \dagger-2$ 
match. Note that the most serious defect, that at $B$, gives a magnetic indication which might very well have been disregarded if the defect had not been known to be there.

In view of the difficulties just indicated, which are typical of the results of previous investigations, and of the fact that wire rope is in itself a rather complicated structure, the investigation has been of a fundamental nature, consisting in a study of the magnetic properties of hard-drawn steel wires of which rope is made and the effect upon them of various influences known to cause deterioration in wire rope in service.

The material used in the investigation was furnished by the American Steel \& Wire Co., and consisted of four grades of patented steel wire known to the trade as "crucible cast steel," "extra strong crucible cast steel," "plow steel," and "monitor plow steel." The wires were 0.1 inch in diameter and had tensile strengths ranging from 190,000 to $250,000 \mathrm{lbs} . /$ in. $^{2}$.

The influences which have so far been made the subjects of study were stress, wear, and fatigue. In view of the fact that under service conditions a hoisting rope is always under stress and that the stress is continually varying while the rope is being used, this element was considered first.

\section{EFFECT OF STRESS}

Although many investigations have been made on the effect of mechanical stress on the magnetic properties of steel and its nature is well known, it is doubtful if the importance of this factor in the field of magnetic analysis has heretofore been fully realized. The results of the present work show very clearly that this element may have a very great influence on the results of investigations on the correlation between the magnetic and mechanical properties of steel.

In order to obtain data on the effect of stress on the magnetic properties of steel wire of the type used in wire rope, measurements were made on samples of wire held under various degrees of tension in a testing machine. The machine used was a Scott horizontal testing machine of 2,000 pounds capacity having a long frame.

The magnetic tests were made by the ballistic method using a straight solenoid and a special test coil. The apparatus is shown in Figure 5. The solenoid was approximately $50 \mathrm{~cm}$ (191/2 inches) long, wound with No. 17 silk-enamel-covered copper wire on a fiber form. The magnetizing force at the middle of the coil was approximately 100 times the current in amperes, and as the coil could carry 10 amperes for short periods without overheating it was possible to use magnetizing forces as great as 1,000 gilberts per centimeter. As the ratio of the length of the specimen to its diameter was well over 200 , the self-demagnetizing effect of the ends could safely be neglected. 
When measurements are to be made with intense fields, the correction due to the flux in the space between the specimen and the test coil becomes very large. In order to avoid the necessity of applying this large correction, a special type of test coil which has been found useful in other work was employed for some of the measurements. In other cases, test coils of 100 turns each were wound directly on the specimen.

The special test coil consists of two parts-coaxial and coextensive longitudinally but of different diameter-so adjusted that their area turns are equal. If these two parts are connected in series opposition to a ballistic galvanometer, and are placed in a uniform magnetic field, there will be no deflection of the galvanometer when the direction of the field is reversed. On the other hand, if there is a specimen

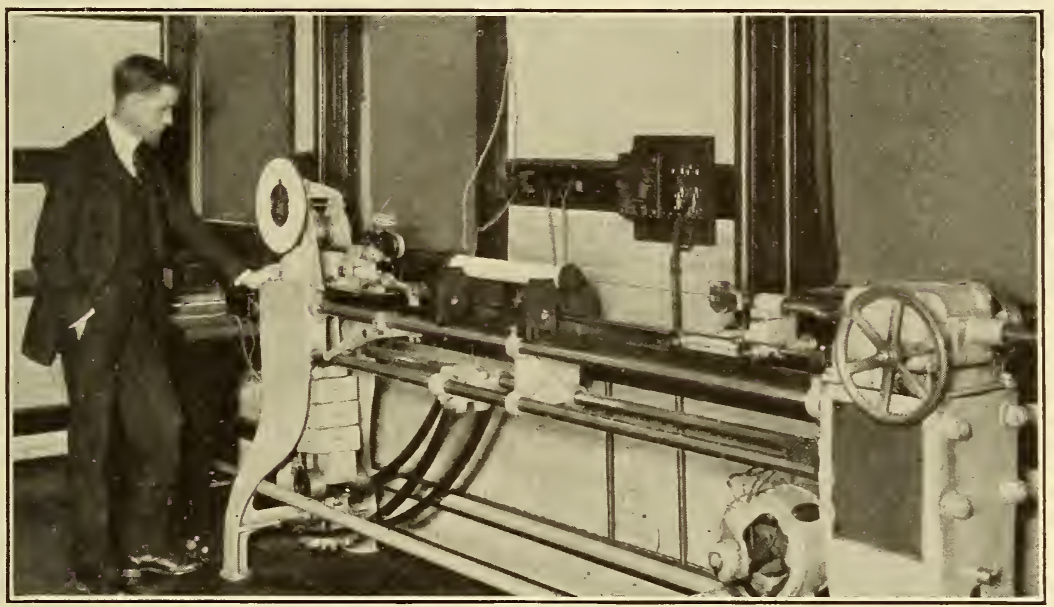

FIG. 5.-Apparatus for determining the effect of stress

in the coil and the field is reversed, the deflection of the galvanometer is proportional to the difference in number of turns of the two parts and the ferric induction $(B-H)$ in the specimen. This is easy to see from the following equations.

Let $A_{1}$ and $A_{2}$, and $N_{1}$ and $N_{2}$ be the area and number of turns of the outer and inner coils, respectively, and $a$ the area of the specimen. $H$ is the magnetizing force and $B$ the flux density in the specimen. The flux turns $(\phi N)$ linked with the two coils are

$$
\begin{aligned}
& (\phi N)_{1}=N_{1} B a+N_{1} H\left(A_{1}-a\right) \\
& (\phi N)_{2}=N_{2} B a+N_{2} H\left(A_{2}-a\right)
\end{aligned}
$$

Since the coils are connected in opposition, the flux turns indicated by the ballistic galvanometer upon reversal will be

$$
(\phi N)=(\phi N)_{1}-(\phi N)_{2}=\left(N_{1}-N_{2}\right) B a+H\left(N_{1} A_{1}-N_{1} a-N_{2} A_{2}+N_{2} a\right)
$$


Since

$$
\begin{aligned}
N_{1} A_{1} & =N_{2} A_{2} \\
(\phi N) & =\left(N_{1}-N_{2}\right) B a-\left(N_{1}-N_{2}\right) H a \\
& =a\left(N_{1}-N_{2}\right)(B-H)
\end{aligned}
$$

The galvanometer is calibrated by means of a standard mutual inductance whose secondary is in the test-coil circuit and its sensitivity is adjusted by resistances so that $1 \mathrm{~cm}$ deflection corresponds to the reversal of a flux density $B=1,000$ gausses. The control apparatus and ballistic galvanometer are shown in Figure 6. Table 1 gives a typical set of test results for one grade of wire.

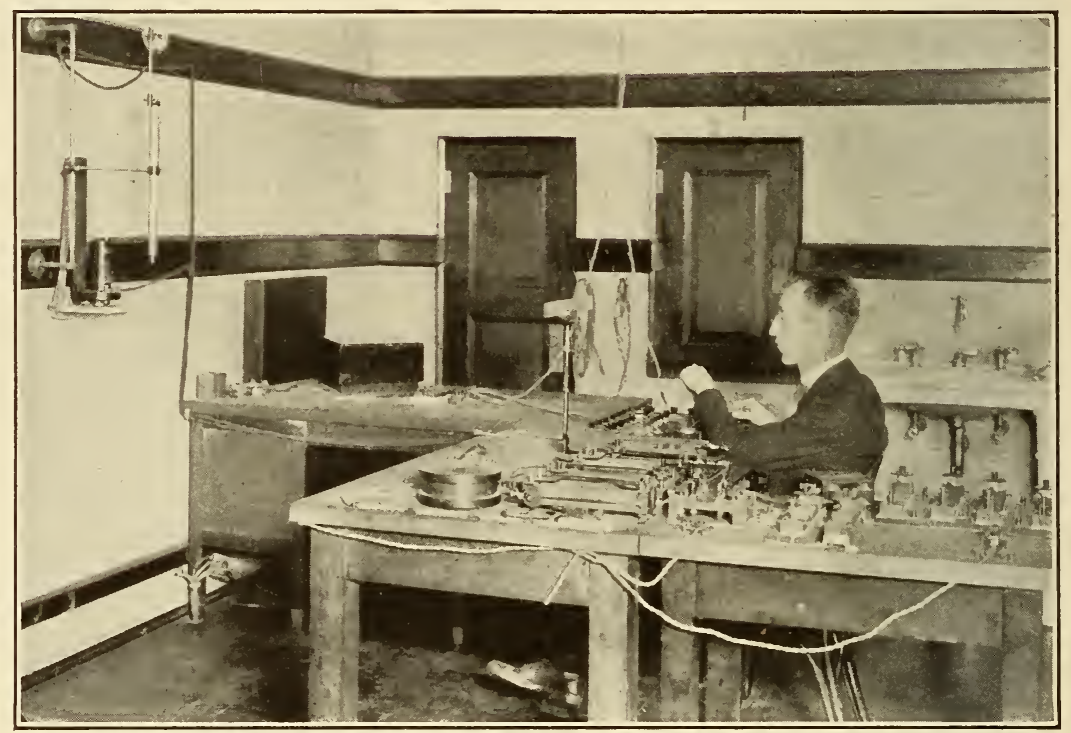

FIG. 6.-Control apparatus and ballistic galvanometer for magnetic induction measurements

\begin{tabular}{|c|c|c|c|c|c|c|}
\hline \multirow{2}{*}{$H$} & \multicolumn{6}{|c|}{ Tensile stress in pounds per square inch } \\
\hline & 0 & 25,500 & 51,000 & 76,500 & 102,000 & 127,500 \\
\hline $\begin{array}{l}5 \\
10 \\
15 \\
20\end{array}$ & $\begin{array}{r}370 \\
1,120 \\
2,500 \\
5,600\end{array}$ & $\begin{array}{r}460 \\
1,430 \\
4,300 \\
8,650\end{array}$ & $\begin{array}{r}480 \\
1,500 \\
5,300 \\
9,600\end{array}$ & $\begin{array}{r}500 \\
1,600 \\
4,850 \\
9,300\end{array}$ & $\begin{array}{r}470 \\
1,500 \\
3,600 \\
7,500\end{array}$ & $\begin{array}{r}490 \\
1,500 \\
3,600 \\
5,700\end{array}$ \\
\hline $\begin{array}{l}25 \ldots \\
30-\cdots \\
40-\cdots \\
50-\ldots\end{array}$ & $\begin{array}{r}8,100 \\
10,000 \\
12,400 \\
14,050\end{array}$ & $\begin{array}{l}10,820 \\
12,150 \\
14,000 \\
15,150\end{array}$ & $\begin{array}{l}11,800 \\
12,970 \\
14,400 \\
15,150\end{array}$ & $\begin{array}{l}11,550 \\
12,700 \\
14,050 \\
14,750\end{array}$ & $\begin{array}{r}9,850 \\
11,400 \\
13,170 \\
14,000\end{array}$ & $\begin{array}{r}9,100 \\
10,600 \\
12,400 \\
13,320\end{array}$ \\
\hline $\begin{array}{l}75 \\
100 \\
1500\end{array}$ & $\begin{array}{l}16,520 \\
17,600 \\
18,640 \\
19,200\end{array}$ & $\begin{array}{l}16,620 \\
17,300 \\
18,250 \\
18,850\end{array}$ & $\begin{array}{l}16,200 \\
16,900 \\
17,780 \\
18,400\end{array}$ & $\begin{array}{l}15,700 \\
16,370 \\
17,280 \\
17,940\end{array}$ & $\begin{array}{l}15,150 \\
15,880 \\
16,800 \\
17,500\end{array}$ & $\begin{array}{l}14,600 \\
15,350 \\
16,350 \\
17,030\end{array}$ \\
\hline
\end{tabular}

TABLE 1.-Values of magnetic induction (B) for various degrees of stress for crucible-cast-steel wire 
In Figure 7 are shown graphically the results for no load and for a load giving a stress of 51,000 lbs/in. ${ }^{2}$. The magnetic induction $(B)$ is increased by tension for the lower values of magnetizing force $(H)$, but the curves cross and for higher values of magnetizing force the magnetic induction is reduced by tension. With these data before us it is easy to see how the effects of stress may interfere with the proper estimation of mechanical quality in terms of magnetic properties. We can now explain the small apparent effect of the notch filed at $B$ in record No. 4 of Figure 4 . The normal effect of the reduction in area would be an apparent decrease in the magnetic permeability. Actually, however, on account of the higher stress,

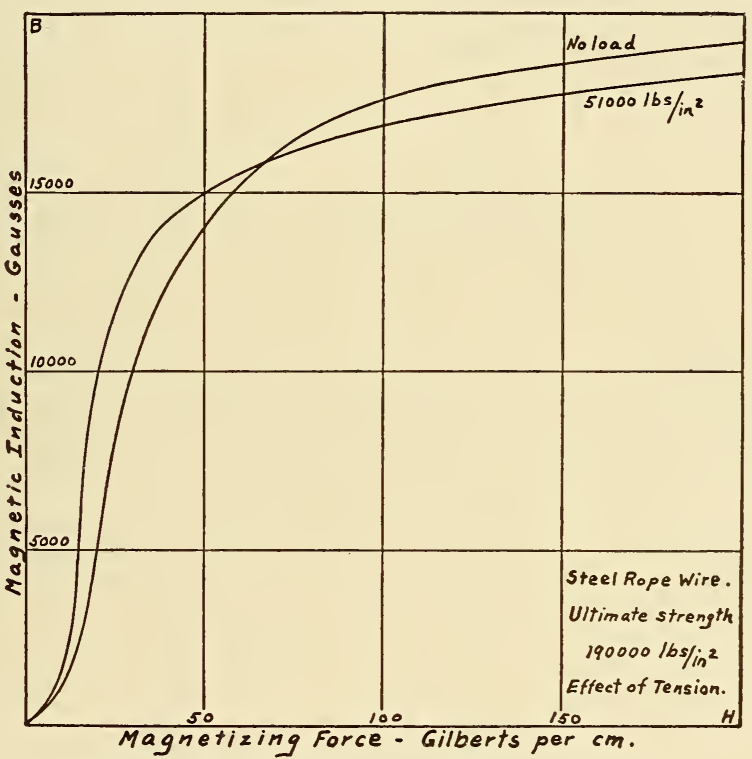

FIG. 7.-Effect of stress on magnetic induction

the permeability of the remaining material is higher and the two effects about neutralize. The irregularities in record No. 3 of Figure 4 can also be explained as the result of variations in stress conditions along the length of the sample. It is very evident that, before the records of magnetic exploration can be interpreted with confidence, some way must be found of eliminating from the records the effects of stress or, failing this, of identifying and evaluating them.

In Figures 8 and 9 the data of Table 1 are plotted to show the change in induction due to tension. In Figure 8 the change is plotted against magnetizing force for two values of stress, one below the elastic limit and the other above it. It will be noted that the maximum effect occurs at about the same magnetizing force in both cases. but that the reversal of sign does not occur at the same value 
of magnetizing force. In Figure 9 the change in induction for the three different values of magnetizing force is plotted against the tension. It will be noted that the effect is large for all values of tension at a magnetizing force of 20 gilberts per centimeter, but

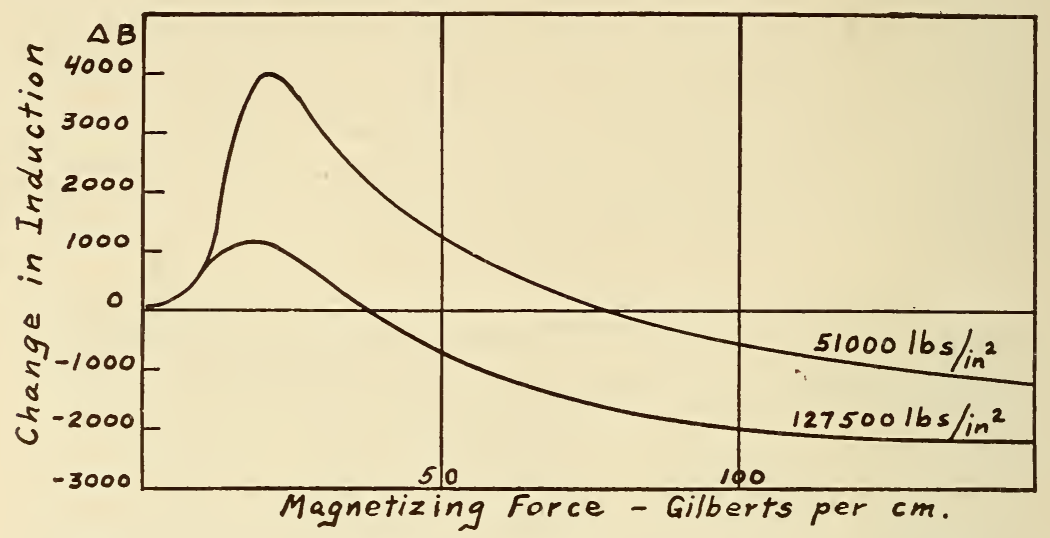

FIG. 8.-Showing the effect of tensile stress on magnetic induction $\triangle B$ is the change of induction at a given magnetizing force

that if a magnetizing force as high as 75 gilberts per centimeter is used the effect is practically negligible for loads up to 50,000 lbs./in. ${ }^{2}$ or more. If this is the case, there should be little irregularity in an exploration record if a magnetizing force as great as 75 gilberts per

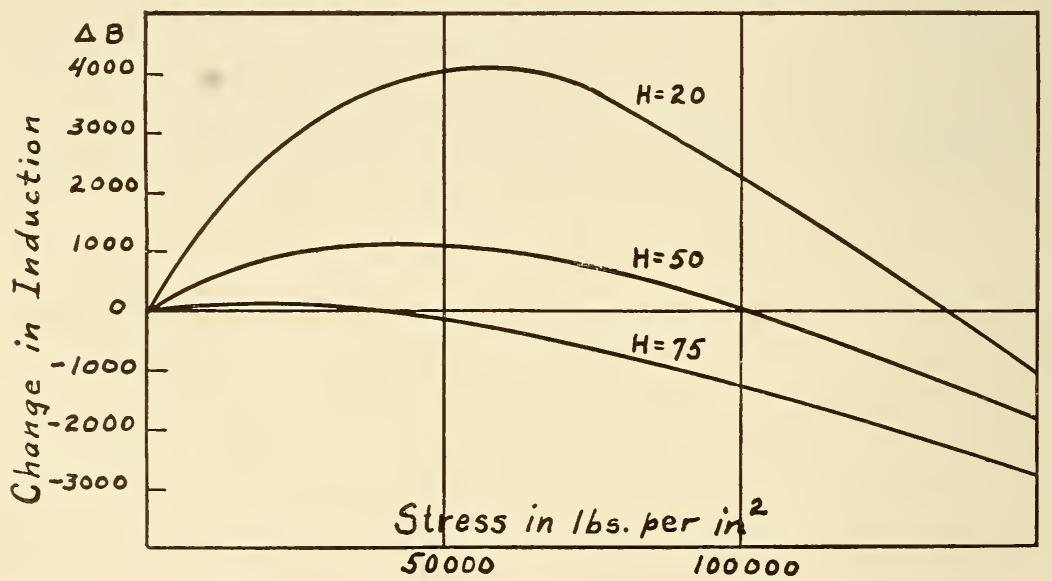

FIG. 9.-Showing the relation between stress and the change in magnetic induction $\triangle B$ for three values of magnetizing force

centimeter is used. This was tried and the results are shown in Figure 10. The wire was the same one as used for records Nos. 3 and 4 in Figure 4 . The upper record was made with a magnetizing force of about 20 gilberts per centimeter and the lower one was made 
with about 100 gilberts per centimeter. In the lower record, the amplitude of the deflections not due to flaws is greatly reduced but the effect of the flaws is still definite and distinct. It appears, therefore, that the effect of variations in the stress distribution which may arise from variable conditions during the process of manufacture, and which do not constitute defects from the practical point of view, may be eliminated by the use of a sufficiently high value of magnetizing force in making magnetic-exploration records. It is probably safe to assume also that effects which are evident at low magnetizing forces but which disappear at high magnetizing forces are due to variations in stress distribution. It would not be desirable to eliminate the

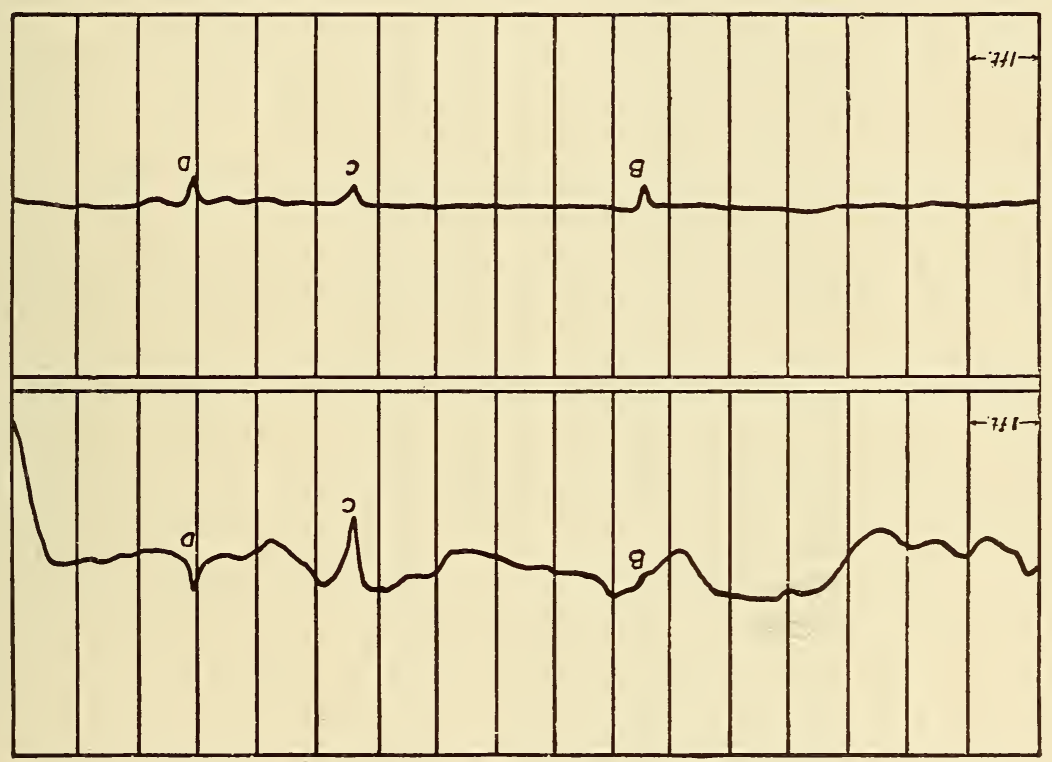

FIG. 10.-Elimination of stress effects by the use of higher magnetizing force

effect of stresses beyond the elastic limit, as stresses of such a magnitude constitute a source of danger. It can be seen from the curves of Figure 9, however, that the change in induction for stresses beyond about $75,000 \mathrm{lbs} . / \mathrm{in} .^{2}$ are not negligible for high values of magnetizing force and would, therefore, appear in the records, taken at high values.

The observations were extended to higher values of magnetizing force for the purpose of studying the effects of stress in the light of the reluctivity relationship. This empirical relationship, which holds for pure homogeneous materials, states that the metallic reluctivity, $\rho=\frac{H}{B-H}$, is a linear function of the magnetizing force for magnetizing forces above a certain minimum value. That is

$$
\rho=a+\beta H
$$


where $a$ and $\beta$ are constants characteristic of the material. It was found that if the material is composed mainly of two longitudinal components, one of which is in tension and the other in compression, the relationship is no longer linear but hyperbolic. It was found possible to resolve the curve into two straight lines, each representing the magnetic properties of one of the components, and to estimate roughly the relative proportions of material in tension and in compression. It was concluded that the wire as received had a relatively thin outer layer in a high degree of tension, balanced by the major portion of the cross section which was in a state of compression of much less intensity. This inhomogeneity as regards condition of stress results in a loss in apparent strength, because the whole of the wire never becomes simultaneously effective in carrying the load. At the elastic limit about half of the material is still in compression and the rest is beginning to fail.

The results of this part of the investigation were reported in more detail in a previous paper. ${ }^{2}$

From the foregoing it can easily be seen that the effect of mechanical stress upon the magnetic properties of steel, which at first was considered as a minor phase of the problem, is of far-reaching importance not only in the present case, but also in the general field of magnetic analysis. Indeed, it does not seen unreasonable to attribute a large part of the difficulty encountered in the attempt to establish definite relationships between magnetic and mechanical properties to this factor. For many times it has been found possible to differentiate magnetically between two samples of steel whose mechanical properties appeared to be alike. Such cases might easily be accounted for by differences in stress conditions not sufficiently great to modify the mechanical properties to an appreciable extent, but having a relatively large effect on the magnetic properties.

\section{EFFECT OF WEAR}

The most obvious result of service in a hoisting rope is wear. This may occur on the outside of the rope where it is visible, or it may take place on the inside where it can not be seen. In either case, it removes material and weakens the rope. Wear does not take place uniformly along the length of an individual wire but is concentrated at points where it comes in contact with other objects. We have already seen in Figure 4 that the magnetic effect of a reduction in section may not be proportional to the amount of material removed. It is also conceivable that the removal of material from the outside of a wire may so modify the stress distribution within the wire as to change its mechanical effectiveness. In order to

${ }^{2}$ Sanford, B. S. Sci. Paper No. 496: 1924. 


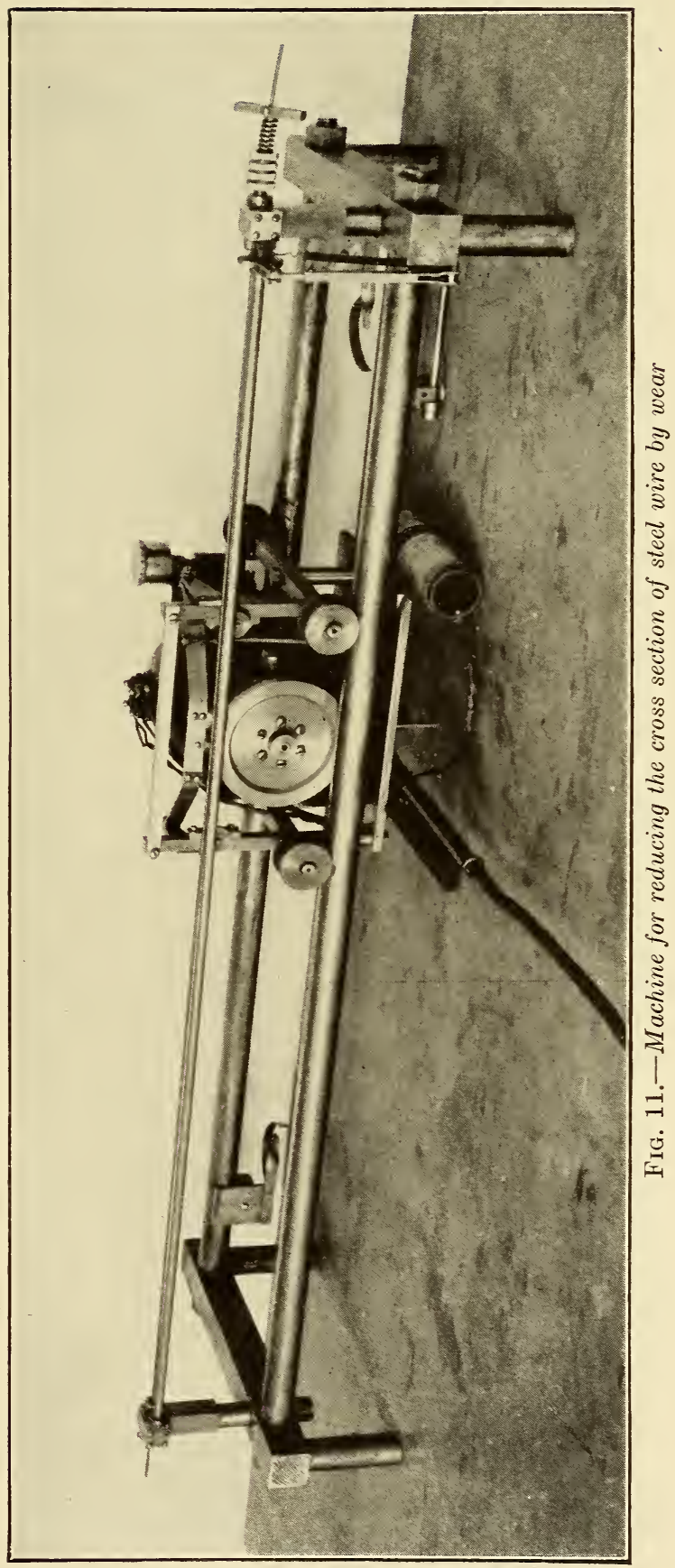


study the phenomena associated with wear under controlled conditions, a machine was constructed by means of which the cross-sectional area of a wire could be uniformly reduced by rubbing against a steel wheel along a sufficient length to permit of making magnetic measurements. The circular section of the wire is maintained by rotating it about its axis during the wearing process. The machine is shown in Figure 11. The details of this machine and of the experiments on wear have been described previously, ${ }^{3}$ but for the sake of

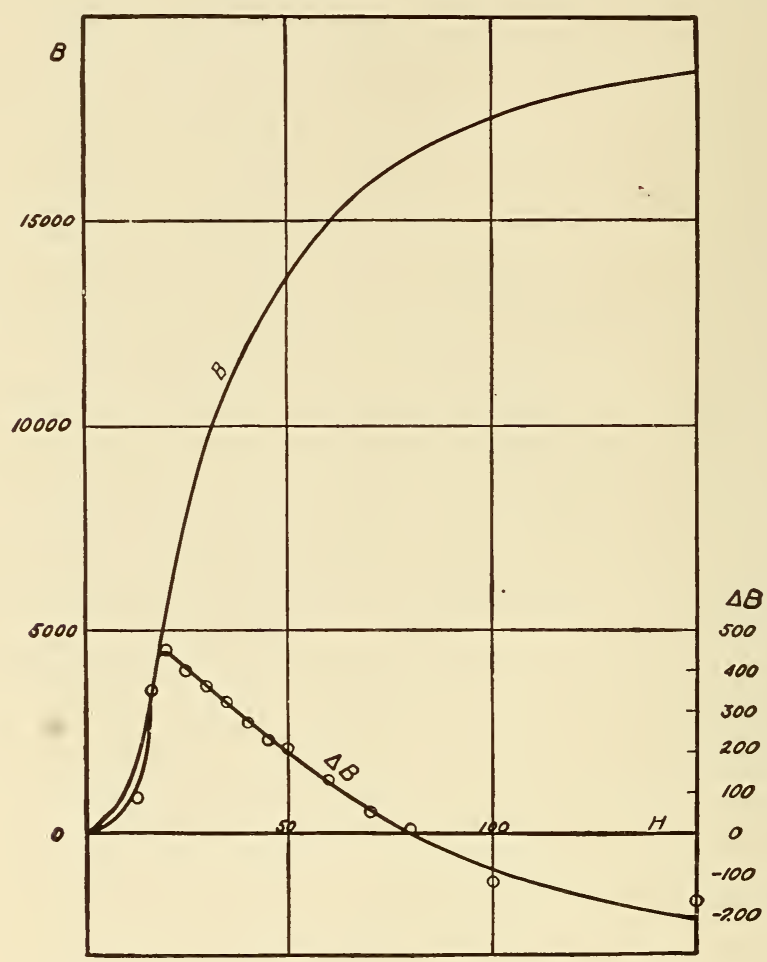

FIG. 12.-Effect of a 17 per cent reduction of area by wear on the magnetic properties of steel wire

$\Delta B$ is the change in induction at a given magnetizing force

completeness the salient features will be given here. Samples of wire after having been tested magnetically were worn down in the machine. At intervals the samples were removed and magnetic tests were made. The nature of the change in magnetic properties is shown in Figure 12, $\Delta B$ being the change in induction. The change is similar in kind, but very much less in magnitude than that resulting from the application of a tensile force. It was found that the maximum change occurred at the same value of magnetizing force $(H=20)$ 
as for tension. The relation between this change in magnetic induction for $H=20$, and the per cent reduction in area by wear, is shown in Figure 13.

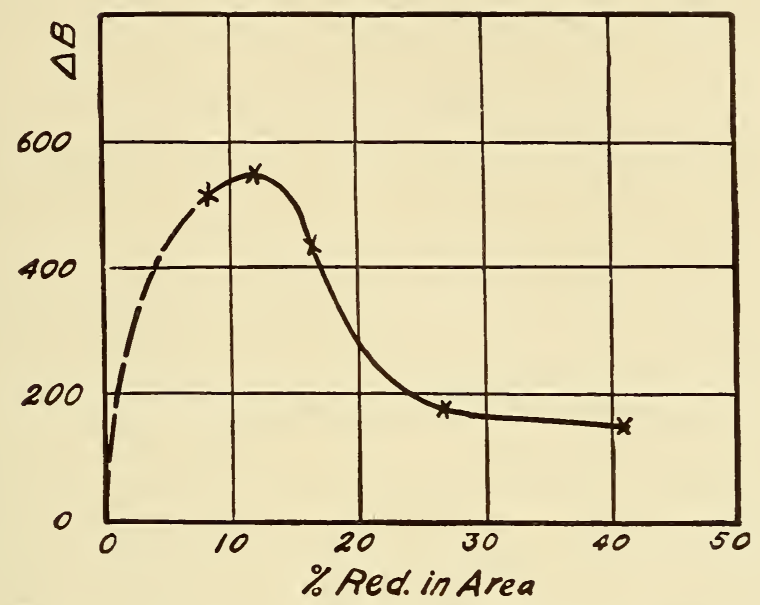

FIG. 13.- Relation between per cent reduction in area by wear and change in magnetic induction for $H=20$

$\Delta B$ is the change in induction

The effect of reduction in area by wear on the tensile strength was also determined approximately by breaking in the testing machine a series of samples which had been worn down by varying amounts. The results are shown in Figure 14 and confirm the expectation that

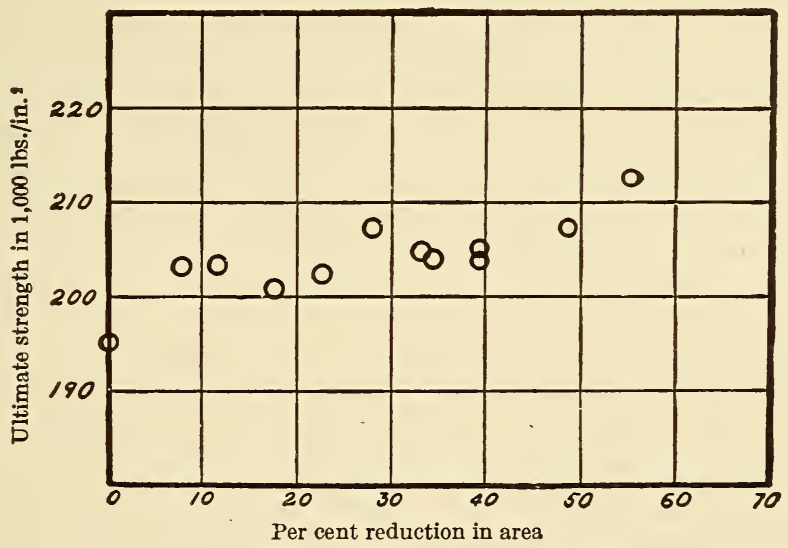

FIG. 14.-Increase in tensile strength of steel wire resulting from reduction in area by wear

the redistribution of stress resulting from the removal of some of the material might result in an increase in the tensile strength in pounds per square inch, although, of course, the total breaking load was decreased. 
With regard to the bearing of this element on the results of magnetic exploration, it was concluded that ambiguity could be avoided, as in the case of stress, by making the tests at a sufficiently high value of magnetizing force.

\section{EFFECT OF REPEATED STRESS}

One of the principal causes of deterioration of wire rope in hoisting service is fatigue due to repeated stress. The repeated stresses result not only from the direct load and vibration, but also from bending over sheaves and drums. There is at present no method for detecting the near approach of failure due to fatigue. It has been said ${ }^{4}$ that "a magnetic test may be expected to follow the changes in structure from the initial perfect condition through the various stages of fatigue to the final rupture. Such changes would be indicated magnetically, whether they were due to a gradual return to a crystalline equilibrium or to stress effects." So far as the writer is aware, however, there is no experimental evidence that this is so. From what is known of the mechanism of a fatigue failure it would appear that the volume of material involved in the actual failure is such a small part of that tested that the magnetic effect would be too small to detect. On the other hand, the fact that there seems to be a definite "endurance limit" (stress below which failure will not occur even though repeated an indefinitely large number of times) characteristic of the material might indicate the possibility of a general change in structure which could be followed magnetically.

During the present investigation only preliminary experiments on this point have been carried out. A sample of tool steel of unknown composition was tested in a rotating beam machine of the Farmer type. ${ }^{5}$. Normal induction measurements were made, before the fatigue test was started, after 501,300 repetitions of stress and again after 543,500 repetitions. The maximum fiber stress was $32,200 \mathrm{lbs}$. $/ \mathrm{in}^{2}$. The 501,300 repetitions resulted in a small increase in permeability in the lower part of the magnetization curve, but no change beyond about $H=50$. The maximum increase was about $31 / 2$ per cent; 42,200 more repetitions produced no further magnetic change although at this point the material was so near failure that it broke while the machine was being started the next time. It is probable that the change observed after the first run really occurred early in the test and was caused by a redistribution of stress across the section, and that there was no further progressive change as the test proceeded.

${ }^{4}$ Burrows, Proc. A. S. T. M., 17, pt. 2, p. 96; 1917.

5 Moore and Kommers, Univ. of Ill. Engr. Exp. Sta., Bul. No. 124; 1921. 
In order to study the matter more in detail with special reference to the material used in the manufacture of wire rope, a Haigh alternating-stress machine, shown in Figure 15, was procured. With this machine, axial load can be applied at the rate of approximately 2,000 times per minute, and the magnetic testing apparatus can be mounted directly on the machine so that magnetic tests can be made at intervals during a run without removing the specimen or even while the machine is running. Preliminary tests have shown no measurable charge in magnetic properties from the start to the oc-

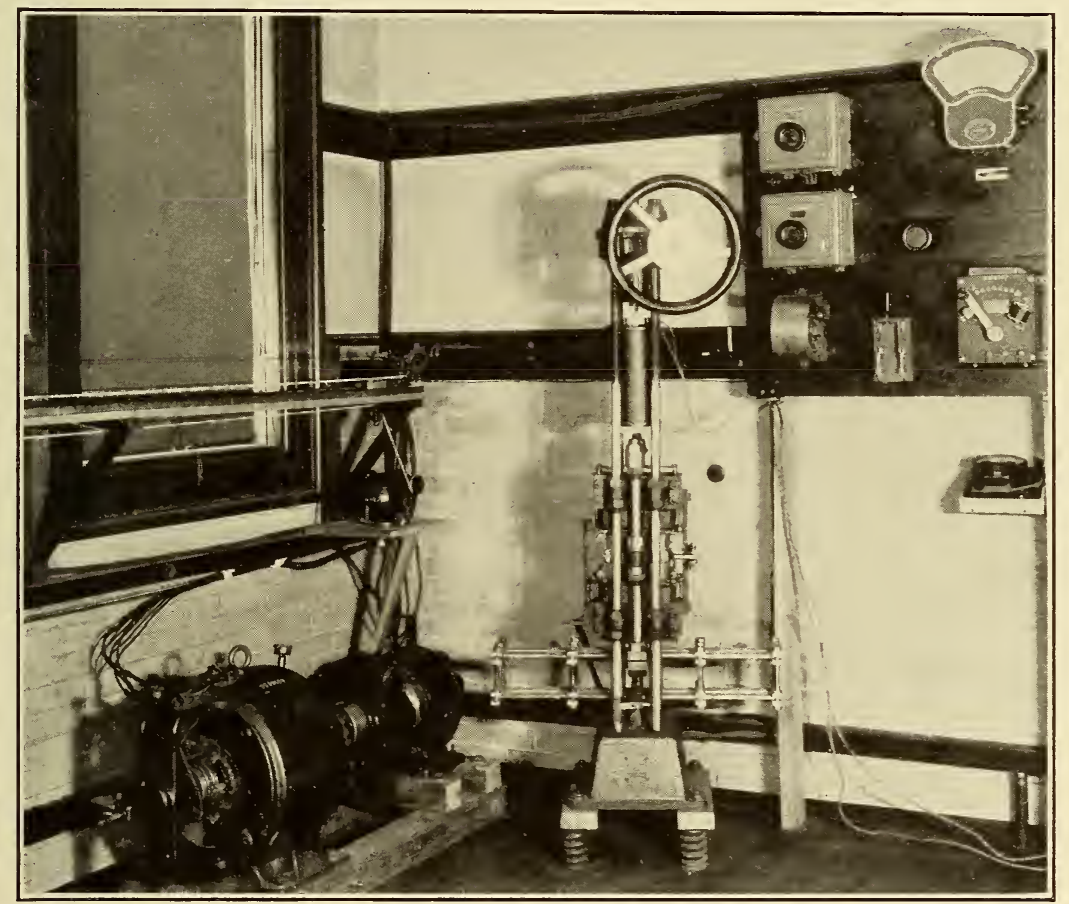

FIG. 15.--Haigh alternating stress machine

currence of failure. In view of the importance of this point in connection with the fatigue properties and testing of materials, in general, this line of work is being continued as a separate investigation.

\section{OTHER EFFECTS}

It has been possible during the present investigation to study only a few of the elements of the problem which must be solved before the records obtained by magnetic exploration can be interpreted with sufficient reliability to permit of the use of the method on a practical basis. There are other factors than stress, wear, and fatigue which modify the magnetic and mechanical properties 
of wire rope. Corrosion, cold work, chemical segregation, and a number of less well understood factors must be investigated.

The material represented by record No. 1, Figure 4, is one example. It was found in this case that the magnetic variations increased in magnitude if the magnetizing force was increased. This would appear to indicate that the irregularities were not due to internal stress. A definite periodicity in the curve was noted which was finally found to be associated with the circumference of the 8-inch roll with which the wire was rolled from the round to the stream-line section. Two other wires from the same source gave practically identical curves. In this case variations in magnetic permeability of considerable magnitude were probably the result of relatively small variations in the amount of cold work, resulting in permanent deformation as distinguished from the temporary condition of stress within the elastic limit, and did not indicate a dangerous condition.

Thus it is seen that the reactions of the magnetic properties of steel to various influences do not necessarily correspond either in direction or magnitude with the effect of these influences on the mechanical properties.

The principal clue to the interpretation of the records lies in the difference in magnetic effect according to the intensity of the magnetizing force used. The records of Figure 10 are illustrative of this point. The effect of the notch at $B$ is small at a low magnetizing force and more pronounced but in the same direction at the higher force. The bend at $C$ produced a large effect at the lower force and a smaller one in the same direction for the higher force. The heating at $D$ caused an increase in permeability at the lower magnetizing force, but a decrease of about the same magnitude for the higher magnetizing force. Whether this method of analysis can be developed to such an extent that the various mechanical effects can be identified and evaluated in terms of the corresponding magnetic effects remains to be determined. Until such a basis for the in terpretation of the results has been established, however, magnetic exploration would appear to have a very limited value as a practical method for the inspection of wire hoisting rope or any similar application.

\section{SUMMARY AND CONCLUSIONS}

Although the present investigation did not result in the development of a magnetic device for testing wire hoisting rope, certain definite results were obtained which have an important bearing not only on this problem, but also on the general subject of magnetic analysis. 
1. Mechanical stress exerts a marked influence upon the magnetic properties of steel. The effect is most pronounced in the lower part of the magnetization curve, and to it may be attributed much of the difficulty heretofore experienced in the attempt to discorer definite relationships between the magnetic and mechanical properties of steel. The effect of a tensile stress well below the elastic limit is sufficient to more than double the magnetic permeability at a certain value of magnetizing force. Slight variations in stress conditions along the length of a specimen, therefore, often give rise to irregularities in the records of magnetic exploration tests which can not be distinguished from those resulting from flaws. This stress effect is negligible if higher values of magnetizing force are used. The proper value for a given material can be ascertained by trial, but 100 gilberts per centimeter is usually sufficient to eliminate the ambiguity due to stress effects.

2. The reluctivity relationship is useful for indicating something of the homogeneity of a specimen across the section. If the reluctivity plotted against the magnetizing force is a straight line, then the material is magnetically pure and homogeneous. If the line is curved, the material is not homogeneous and the degree of inhomogeneity can be judged by the amount of curvature. If the only source of inhomogeneity is longitudinal stress, as is the case of wire used in rope, then it is possible to resolve the curve into the two straight-line components and estimate the relative proportions in tension and compression, respectively.

3. The effect of wear is to reduce the cross-sectional area. The result is a modification of the magnetic properties. Also, the breaking load is decreased, but not in proportion to the decrease in area, so that the tensile strength in pounds per square inch is actually increased. Ambiguity in exploration records due to this cause can be avoided by using sufficiently high values of magnetizing force.

4. Experimental evidence so far obtained indicates that the near approach to failure by fatigue is not accompanied by a corresponding change in magnetic properties by which the condition could be recognized.

5. A single broken wire, either on the outside of a rope or in the interior, produces a distinct magnetic effect, but, since the magnetic effect of a broken wire generally can not be distinguished from that due to other causes, the results of a magnetic test are not conclusire on this point.

6. The effect of cold work has not been studied specifically in the present inrestigation, but it is known from the results of other work that slight variations in the amount of work done on the specimen 
result in relatively large variations in magnetic permeability. The magnetic effect increases with higher values of magnetizing force. Ambiguity due to this cause can not, therefore, be removed as in the case of stress and wear by the use of high magnetizing forces.

7. As a research method for use in the study of the properties of wire rope and other materials, magnetic analysis has undoubted value. There are as yet so many sources of uncertainty, however, that there seems to be no immediate prospect of the development of a magnetic method for the inspection of wire rope of a sufficient degree of reliability to warrant its use on a commercial basis.

Washivgton, January 19, 1926. 